\title{
Mo KN1
}

\section{Highly Focused Fluid Flow across Thick Low}

Permeability Sequences

\section{J. Cartwright* (University of Oxford)}

\section{SUMMARY}

In the past two decades, the wide availability of $3 \mathrm{D}$ seismic data for research purposes has resulted in a comprehensive documentation of a wide variety of geological features that can be attributed to highly focused fluid expulsion. 


\section{Introduction}

In the past two decades, the wide availability of 3D seismic data for research purposes has resulted in a comprehensive documentation of a wide variety of geological features that can be attributed to highly focused fluid expulsion. These features have been referred to as seal bypass systems, since they allow significant flux of fluids, including hydrocarbons, to bypass the matrix permeability of classically sealing lithologies. Seal bypass systems include faults and fractures, which are well known to have acted as fluid flow conduits, but also include less well documented conduits such as fluid escape pipes, and sedimentary intrusions.

This presentation reviews the current understanding of seal bypass systems, and presents examples observed on 3D seismic from a diverse range of basins from contrasting tectonic settings. The geometry of these features is described and contrasted, and evidence is presented that they have acted as important fluid escape valves for sedimentary basins over long periods of basin evolution. The presentation concludes with a discussion of what major research questions are outstanding as to the behaviour and genesis of seal bypass systems. 